\title{
Effects of Temperature and Humidity on Laser Diffraction Measurements to Jet Nebulizer and Comparison with NGI
}

\author{
Xinghan Song, ${ }^{1,3}$ Junhua Hu, ${ }^{1,3}$ Shuyao Zhan, ${ }^{1,3}$ Rui Zhang, ${ }^{1,3}$ and Wen Tan ${ }^{1,2,3,4} \mathbb{C}$
}

Received 17 March 2015; accepted 30 May 2015; published online 14 July 2015

Abstract. Laser diffraction (LD) and next generation impactor (NGI) are commonly used for the evaluation of inhaled drug formulations. In this study, the effect of temperature and humidity on the assessment of the nebulizer particle size distribution (PSD) by LD was investigated, and the consistency between NGI and LD measurements was evaluated. There was an increase in particle size with higher temperature or lower humidity. The particle population with a diameter less than $1 \mu \mathrm{m}$ was significant at a temperature of $5^{\circ} \mathrm{C}$ or at relative humidity $>90 \%$; however, the same particle population became undetectable when temperature increased to $39^{\circ} \mathrm{C}$ or at relative humidity of $30-45 \%$. The results of the NGI and LD measurements of aerosol generated from three types of jet nebulizers were compared. A poor correlation between the NGI and LD measurements was observed for PARI LC $(2.2 \mu \mathrm{m})\left(R^{2}=\right.$ $0.893)$ and PARI LC $(2.9 \mu \mathrm{m})\left(R^{2}=0.878\right)$, while a relatively good correlation $\left(R^{2}=0.977\right)$ was observed for the largest particle size nebulizer (PARI TIA $(8.6 \mu \mathrm{m})$ ). We conclude that the ambient environment and the nebulizer have significant impacts on the performance and consistency between these instruments. These factors should be controlled in the evaluation of inhaled aerosol drug formulations when these instruments are used individually or in combination.

KEY WORDS: impactor; jet nebulizer; laser diffraction; particle size distribution.

\section{INTRODUCTION}

Pulmonary delivery is an important means for drug administration. Its advantages include direct administration to the site of action, rapid onset, avoidance of the first pass effect, and higher efficiency of the delivered drug. There are three types of formulations used for pulmonary delivery: pressurized metered dose inhalers (pMDI), dry powder inhalers (DPI), and nebulizers (13). pMDI is released at high velocity and requires a simultaneous inhalation by the patient. DPI requires a relatively high inspiratory flow rate to delivery an effective mass fraction of fine particles (2). These two types of therapy may not be suitable for young children and elderly $(2,4)$. Conversely, nebulizers may have a broader application for different patient groups and diseases, due to ease of use and high patient compliance despite some drawbacks such as long time to nebulization $(5,6)$.

Xinghan Song and Junhua Hu contributed equally to this work.

${ }^{1}$ Pre-incubater for Innovative Drugs and Medicine, South China University of Technology, Guangzhou, Guangdong, China.

${ }^{2}$ Guangdong Provincial Key Laboratory of Fermentation and Enzyme Engineering, South China University of Technology, Guangzhou, Guangdong, China.

${ }^{3}$ School of Bioscience and Bioengineering, South China University of Technology, Guangzhou, Guangdong, China.

${ }^{4}$ To whom correspondence should be addressed. (e-mail: hujunhua19900404@163.com)
There are three basic types of nebulizers based on the aerosol generator, the jet, the mesh, and the ultrasonic nebulizer. The mesh nebulizer uses a vibrating mesh or plate with multiple apertures to generate a liquid aerosol (7). The jet nebulizer uses compressed air to aerosolize the drug solution, whereas the ultrasonic nebulizer uses energy from highfrequency sound waves $(2,5)$. Studies have reported that the size of the aerosol particles generated by the ultrasonic nebulizer is larger than those from a jet nebulizer $(8,9)$. In clinical settings, larger particles may not be suitable for deep lung deposition. The size of aerosol particles generated by the jet nebulizer is directly proportional to the compressed air flow and the size of the nozzle, and a much smaller particle size can be generated. In addition, the particle size can be easily adjusted by choosing different types of jet nebulizers to meet the clinical need (10). Mesh nebulizers has a greater efficiency, precision, and consistency of drug delivery to the lung than jet nebulizer and ultrasonic nebulizer. However, the higher cost of these devices has limited the generalization of mesh nebulizer. On the other hand, mesh nebulizer can be less efficient in nebulizing suspensions because of the blockage of the minute apertures with drug particles (7). Currently, the jet nebulizer is widely used in clinical applications in spite of low efficiency of the drug delivery (11).

To meet different clinical needs for drug deposition in pulmonary delivery therapy, the size of aerosolized particles must be controlled. The preferred size range for aerosolized particles depends on the target area. For instance, particles with an aerodynamic diameter larger than $5 \mu \mathrm{m}$ deposit mainly in the 
oropharyngeal region, and a particle size less than $2 \mu \mathrm{m}$ is ideal and is able to deposit in the peripheral airways. However, some particles $(<0.5 \mu \mathrm{m})$ are likely to be exhaled $(10,12)$.

Clearly, precise and accurate measurement of particle size distribution (PSD) is critical for the evaluation of pulmonary formulations $(3,13,14)$. Various in vitro characterization methods have been recommended for the measurements of particle size distribution (PSD). The traditional particle size analysis in the United States Pharmacopeia (USP) and European Pharmacopeia utilizes the impactor, which has been currently considered as "the golden standard" for inhaler testing because they yield mass fractions of the drug dose (by chemical detection) in aerodynamic size classes that are relevant to particle deposition in the human respiratory tract. With a constant flow rate, the airborne particles travel through several stages with progressively decreasing cut sizes. The deposition behavior of particles is relevant to the combined effect of inertial impaction, gravitational sedimentation, and diffusion by way of Brownian motion (15-21), giving more realistic simulation of impaction in the lungs. It is obvious that aerodynamic size distribution is an important parameter affecting aerosol performance.

In the proposed European Pharmacopeia, the measurement of PSD for nebulizers must specify a fixed flow rate of $15 \mathrm{~L} / \mathrm{min}$ by a multi-stage impactor. Presently, the next generation impactor (NGI) is the only commercially available impactor to meet the requirement above. Others, such as the Anderson cascade impactor (ACI), do not meet this requirement for nebulizer testing because they require a minimum flow rate of $28.3 \mathrm{~L} / \mathrm{min}$ for normal operation $(14,22)$.

Laser diffraction (LD) provides a rapid measurement of droplet diameter when aerosol passes through the laser beam. The different intensity and angles of the light diffraction pattern are captured by photodetector. The data is used to calculate the solution to the Mie equations that are the combined vector equations for the incident wave, the scattered wave, and the wave inside the droplet. These information are directly related to the particle properties. LD provides droplet volume median droplet diameter (VMD) which is relevant to the particle shape, particle density, and other physical properties (viscosity, hygroscopicity, and aggregation); these information are essential for formulation development (14, 16, 23-25). There are many studies confirmed that the most profitable features of laser diffraction are time saving, reproducibility, automatic data recording, and automatic processing. Furthermore, the applicability of laser diffraction technique is evaluated as an alternative for cascade impactor analysis for the in vitro characterization of various types of medical aerosol generators (15, 26-31). Some commonly used laser diffractometers are the Spraytec laser diffractometer (Malvern Instruments, UK) and the Sympatec HELOS laser diffraction analyzer (Sympatec $\mathrm{GmbH}$, Clausthal-Zellerfeld, Germany) (14).

However, the operation conditions of laser diffraction are still uncertain in the proposed pharmacopeia. Environmental conditions such as temperature and humidity not only may influence variability of the aerosol generation but also may influence PSD during the process of measurement. Relative humidity will influence triboelectric effects for DPI (32-34), and together with temperature it will also affect aerosol evaporation during the process of measurement of pMDIs and nebulizers (35). Farzin et al. investigated in vitro mouth- throat deposition and lung delivery of selected solution and suspension pMDI formulations by using the Alberta Idealized Throat under a range of relative humidity, temperature, and flow rate conditions. The results showed that not only is the dose delivery of pMDI formulations affected by environmental conditions (in some cases causing up to $50 \%$ reduction in lung delivery) but also the solution and suspension formulation behaved differently in response to these conditions (36). Kwong et al. compared the nebulized particle size distribution with Malvern laser diffraction analyzer (Malvern Mastersizer $\mathrm{X}$; MMX) versus Andersen cascade impactor and a low flow marble personal impactor which at that time was proposed as the European standard for wet aerosol analysis to minimize evaporative losses during sampling. Mass median diameters (MMDs) obtained with the MMX were virtually identical to the mass median aerodynamic diameters (MMADs) measured with both impactors were cooled. They concluded that there was no evidence suggesting a significant evaporative loss of small droplets from the edge of the plume during laser particle sizing (16). Ziegler et al. investigated the evaporation effect of aqueous aerosols on the PSD by using the Sympatec HELOS laser diffraction analyzer at ambient humidity (RH30 $-45 \%$ ) and high humidity (RH $>90 \%$ ), and showed that the influence of the humidity on LD was not negligible (17).

In addition, LD technology applies a different principle compared with NGI. To establish a reliable analysis for formulation assessment, it is important to study the correlation between LD and NGI (26-28). Ziegler et al. studied the correlation between LD and ACI in PSD assessment of nebulizers with soft mist inhalers, which use a spring to push the liquid through a micro-nozzle thus producing an aerosol.

Presently, the correlation between LD and NGI results in PSD assessment of nebulizers has not been reported, even though the latter instrument is more widely used in pharmaceutical practice than ACI (17).

In this study, we investigated the effect of temperature and humidity on the PSD assessment of nebulizer by LD. We also studied the consistence between LD and NGI results in PSD assessment of aerosol generated by jet nebulizer with different particle size ranges. The operation flow rate of LD and NGI instruments were adjusted to a value similar to the EP requirement $(17,22)$. The purpose of this study is to provide a reference for an accurate assessment of nebulizer using either LD or NGI.

\section{MATERIALS AND METHODS}

\section{Materials}

The PARI ${ }^{\circledR}$ Jet nebulizers used were as follows: PARI LC $(\mathrm{MMD}=2.2 \mu \mathrm{m})$, PARI LC $(\mathrm{MMD}=2.9 \mu \mathrm{m})$, and PARI TIA $(\mathrm{MMD}=8.6 \mu \mathrm{m})($ PARI GmbH, Germany). The MMDs are provided by PARI GmbH, which utilized a 1.2 bar compressor and measured with Malvern Mastersizer X using a $0.9 \% \mathrm{NaCl}$ solution and an inspiratory flow $20 \mathrm{~L} / \mathrm{min}$.

Three types of nebulizers with different particle size ranges were investigated using compressed air at a flow rate of $6.0 \mathrm{~L} / \mathrm{min}$ to generate the aqueous aerosols. A Ventolin inhalation solution (the active drug is racemic salbuterol) and the aerosol solution formulation ResQ-1 (the active drug, R-salbuterol was provided by Key-Pharma Biomedical Inc., 
Dongguan, China) was used at a concentration of $2.5 \mathrm{mg} / \mathrm{mL}$. Sodium dihydrogen phosphate (Cheng Du Ke Long Chemical Co., Ltd., Chengdu, China) and methanol (Thermo Fisher Scientific Inc., China) were bought from commercial sources. Two types of standard samples (Thermo, Duke Standards ${ }^{\mathrm{TM}}$ ) with a normal diameter of 1 and $9 \mu \mathrm{m}$ were used to verify the reliability of the laser diffraction apparatus.

\section{METHODS}

\section{Particle Size Calibration}

To verify the reliability of the laser diffraction apparatus (Spraytec, Malvern instruments, UK), two types of standard samples with a normal diameter of 1 and $9 \mu \mathrm{m}$ were used for calibrating the laser diffraction apparatus. The standard samples consist of polymer microspheres of defined sizes. The size distribution of the standard samples was measured with the laser diffraction apparatus; the distributor MAM5020QSpec MU (Malvern instruments, UK) was installed to the sampler, $1 \mathrm{~L}$ of distilled water was filled into the distributor, $2000 \mathrm{rpm}$ was set up in order to disperse the samples, and three drops of standard samples were placed into the distributor.

Various parameters were calculated automatically in the Spraytec software (Malvern instruments, UK) for volumebased size distribution: the particle size below which $10 \%$ of the spray lies (Dv (10)), the particle size below which $50 \%$ of the spray lies (Dv (50)), the particle size below which $90 \%$ of the spray lies (Dv (90)), and Span (the width of the distribution - the narrower the distribution, the smaller the span becomes-is calculated as: $\left.\frac{D v(90)-D v(10)}{D v(50)}\right)$. Values presented are the average of at least three determinations. The results were compared with the nominal values given for the standard samples reference.

\section{Particle Size Characterization by Laser Diffraction}

The volume particle size distribution was measured using a Spraytec LD (Malvern instruments, UK) instrument at different temperatures and humidities. A temperature regulating chamber (JinLiXin Ltd., China) was used to set the temperature $\left(5,25 \pm 2\right.$, and $\left.39 \pm 2^{\circ} \mathrm{C}\right)$ and under ambient humidity (relative humidity RH 50-70\%), and the effect of temperature on aerosol PSD was investigated using the Spraytec. Furthermore, the influence of humidity on the Spraytec aerosol particle size was validated under low humidity (RH30-45\%) and high humidity $(\mathrm{RH}>90 \%)$ using a humidity controller (JinLiXin Ltd., China).

The Spraytec was assembled with the inhalation cell (Malvern instruments, UK) and was placed in the chamber (JinLiXin Ltd., China) at a set temperature or humidity, and the system was incubated for $4 \mathrm{~h}$. The nebulizer was connected to a USP throat at the inlet of the inhalation cell, and a high capacity vacuum pump (HCP5, COPLEY Scientific, UK) calibrated at $15 \mathrm{~L} / \mathrm{min}$ was attached to the outlet of the cell (Fig. 1). The nebulizer was filled with $3 \mathrm{~mL}(4 \mathrm{~mL}$ for the PARI TIA) of inhalation solution and the total aerosol collection time was $5 \mathrm{~min}$.

Various parameters such as Dv (10), Dv (50), and Dv (90) were calculated automatically in the Spraytec software

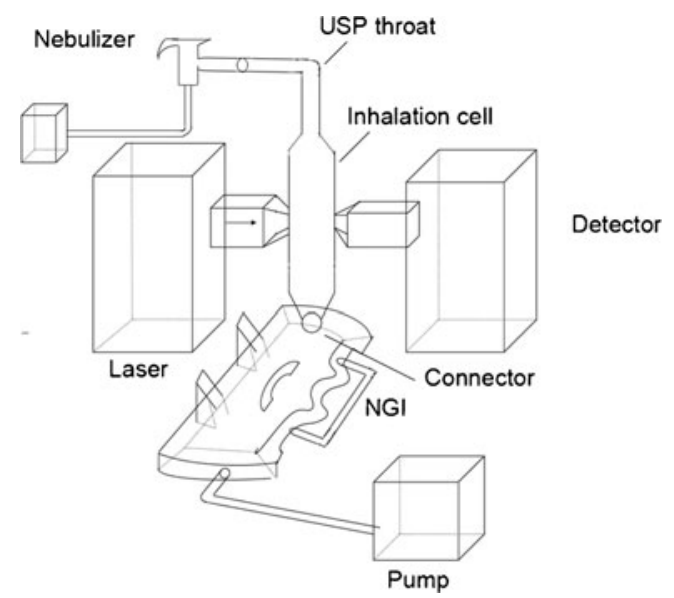

Fig. 1. Front side view of the experimental set-up for simultaneous particle size distribution measurements with NGI and Spraytec

(Malvern instruments, UK). Values presented are the average of at least three determinations.

\section{Particle Size Measurement by NGI}

The NGI (COPLEY Scientific, UK) was operated at $15 \mathrm{~L} / \mathrm{min}$ using a high capacity vacuum pump (HCP5, COPLEY Scientific, UK) to measure the aerosol particle size at $5^{\circ} \mathrm{C}$. The nebulizer was connected to the induction port of the NGI with a mouthpiece adapter, filled with $3 \mathrm{~mL}$ of inhalation solution, and the aerosol collection time was $5 \mathrm{~min}$. When the aerosol finished, the nebulizer was first turned off and then the pump was turned off after $10 \mathrm{~s}$. Once the measurement was completed, the cup holder tray was removed and the samples were washed repeatedly with ultra-pure water (Mili-QA10, USA). The samples were then removed to a volumetric flask and were determined using high performance liquid chromatography (HPLC) $(18,37,38)$. The following parameters were calculated using CITDAS software (COPLEY Scientific, UK): mass median aerodynamic diameter (MMAD), geometric standard deviation (GSD), and fine particle fraction (FPF). MMAD is defined as the diameter at $50 \%$ of the cumulative mass curve which was plotted versus the logarithm of the effective cut-off diameter. GSD is defined as the sharpness of the collection efficiency curve and derived from the square root of the ratio of diameters at $84.13 \%$ and $15.87 \%$ cumulative mass. FPF is defined as the percentage of drug present in the respirable stages of the impactor over the total amount of deliverable drug. Values presented are the average of at least three determinations $(19,37,38)$.

\section{The Correlation Between Inertial Impaction and Laser Diffraction}

To establish the correlation between NGI and Spraytec measurements, a stainless steel connector (ZhengXin Ltd., China) was used to connect the outlet of the inhalation cell to the inlet of a stage-one nozzle (Fig. 1). The connection allowed the same aerosol to be measured simultaneously by the Spraytec and the NGI. The drug deposition recovered on the different stages of the NGI was determined by HPLC. Therefore, particle size could be assessed using the two 
techniques in series. All of the tests were performed with the three different of nebulizers at $15 \mathrm{~L} / \mathrm{min}$ and $5^{\circ} \mathrm{C}$. The values presented are the average of at least three determinations.

\section{Chromatographic Conditions}

The sample was analyzed by HPLC (LC-20A, Shimadzu corporation, Japan) employing a $0.08 \mathrm{~mol} / \mathrm{L}$ sodium dihydrogen phosphate solution ( $\mathrm{pH} 3.10 \pm 0.05)$ and methanol $(85: 15, v / v)$ as the mobile phase with a flow rate of $1 \mathrm{~mL} / \mathrm{min}$. The mobile phase was filtered through a $0.45 \mu \mathrm{m}$ nylon membrane filter (Whatman, UK) under vacuum and degassed prior to use. All the samples were filtered through a $0.45 \mu \mathrm{m}$ nylon membrane filter before injected. The chromatographic column was an Agilent ODS column $(150 \times 4.6 \mathrm{~mm}, 5 \mu \mathrm{m})$, and UV detection at $276 \mathrm{~nm}$ was employed. The column temperature was held at $40^{\circ} \mathrm{C}$. The injection volume was $20 \mu \mathrm{L}$, and the retention time (RT) of the salbuterol was approximately $4.00 \mathrm{~min}$. To evaluate the linearity of the method, seven calibration curves in the concentration range of 0.9765625 to $62.5 \mu \mathrm{g} / \mathrm{mL}(0.9765625,1.953125,3.90625,7.8125$, $15.625,31.25$, and $62.5 \mu \mathrm{g} / \mathrm{mL}$ ) were prepared. The limit of detection (LOD) and limit of quantification (LOQ) was 0.23 and $0.70 \mu \mathrm{g} / \mathrm{mL}$, respectively. The mean linear regression equation was $y=7034.5 x-328.32$ with a correlation coefficient of 1.0000 (39).

\section{Statistical Analysis}

All results are shown as mean \pm standard deviation (S.D). The correlation between the NGI and LD measurements can be fitted by linear regression analysis of data. Two groups were compared using the paired Student's $t$ test and $P<0.05$ was considered significant (SPSS 17.0, SPSS Inc., Chicago, USA).

\section{RESULTS}

\section{Particle Size Calibration of Spraytec}

Two types of polystyrene suspension liquid standard samples (Thermo, Duke Standards ${ }^{\mathrm{TM}}$ ) with normal diameters of 1 and $9 \mu \mathrm{m}$ were used for assessing the reliability of the laser diffraction analyzer. The results of the particle measurements were shown in Table I.
All of the standard sample values measured by Spraytec meet the tolerance interval, showing good reliability of the laser diffraction analyzer.

\section{Influences of Temperature and Humidity on Particle Size Measured by Spraytec}

The particle size distribution of two different inhalation formulations, i.e., Ventolin and formulation ResQ-1, were assessed separately at $5,25 \pm 2$, and $39 \pm 2^{\circ} \mathrm{C}$, and at RH30$45 \%$ and $\mathrm{RH}>90 \%$. The commercially available jet nebulizers, namely PARI LC $(2.2 \mu \mathrm{m})$, PARI LC $(2.9 \mu \mathrm{m})$, and PARI TIA $(8.6 \mu \mathrm{m})$, were selected to study the roles of particular sizes of particle droplets in the above assessment. Tables II and III summarized the changes in the volume of the distribution of particles at $50 \%$ (Dv (50)). The results indicated that temperature and humidity have significant effects on the assessment of particle size at Dv $(50)(P<0.05)$; there was an increase in particle size (Dv (50)) with increasing temperature (Table II). However, humidity has the opposite effect on the measurement. There was a decrease in particle size (Dv (50)) with increasing humidity (Table III).

These effects of changing of temperature and humidity were enhanced when the aerosol droplets were generated from the three jet nebulizers producing different size of particles. The effects of temperature and humidity on particle size measurements are much greater when the PARI TIA $(8.6 \mu \mathrm{m})$ was used compared to the PARI LC $(2.2 \mu \mathrm{m})$ and PARI LC $(2.9 \mu \mathrm{m})$.

The effects on the particle assessments resulting from changing temperature, humidity, and jet nebulizer were similar between Ventolin and formulation ResQ-1.

The assessment of cumulative particle distribution (from Dv (0) to Dv (100)) as well as the distribution of particle size population was also studied using the above conditions. The curve of cumulative distribution of particle volume and curve of frequency distribution of particle size generated at different temperatures (Fig. 2a, b) and humidities (Fig. 2c, d) were presented below. Figure 2a illustrated the cumulative change of percent volume $v s$ the increase of particle size in the aerosol droplet using PARI TIA $(8.6 \mu \mathrm{m})$ and formulation ResQ-1. The results showed that there is a decrease in volume distribution percent of particles when the ambient temperature increased during measurement. The volume distribution measured at $39 \pm 2^{\circ} \mathrm{C}$ differed significantly compared to $25 \pm 2$ and $5^{\circ} \mathrm{C}$ (Table II). There was a right shift of accumulation curves with an increase in ambient temperature. Figure $2 b$ was the

Table I. Comparison of Particle Size Calibration Using a Standard Sample

\begin{tabular}{|c|c|c|c|c|}
\hline $\begin{array}{l}\text { Particle } \\
\text { size }(\mu \mathrm{m})\end{array}$ & $\begin{array}{l}\text { Measurements } \\
\text { (volume distribution) }\end{array}$ & $\begin{array}{l}\text { Actual measured value } \\
n=3(\text { mean } \pm \mathrm{SD}, \mu \mathrm{m})\end{array}$ & Normal value $(\mu \mathrm{m})$ & Tolerance interval $(\mu \mathrm{m})$ \\
\hline \multirow[t]{3}{*}{1} & Dv (10) & $0.884 \pm 0.024$ & 0.858 & $0.807 \sim 0.909$ \\
\hline & Dv $(50)$ & $0.991 \pm 0.004$ & 1.002 & $0.972 \sim 1.031$ \\
\hline & Dv $(90)$ & $1.113 \pm 0.027$ & 1.15 & $1.082 \sim 1.219$ \\
\hline \multirow[t]{3}{*}{9} & Dv (10) & $7.920 \pm 0.006$ & 8.016 & $7.536 \sim 8.496$ \\
\hline & Dv (50) & $8.988 \pm 0.005$ & 8.891 & $8.624 \sim 9.157$ \\
\hline & Dv (90) & $9.657 \pm 0.003$ & 9.634 & $9.056 \sim 10.212$ \\
\hline
\end{tabular}

Two types of polystyrene liquid suspensions were used as standard samples (Thermo, Duke Standards ${ }^{\mathrm{TM}}$ ) whose normal diameter is 1 and $9 \mu \mathrm{m}$ was used for testing the reliability of the laser diffraction analyzer. The results of the particle measurement are shown in Table I 
Table II. Summary of the Value of Dv (50) Obtained with the Spraytec in Different Temperatures by Using Three Types of Nebulizer

\begin{tabular}{|c|c|c|c|}
\hline \multirow[b]{2}{*}{ Device } & \multicolumn{3}{|c|}{ The fifty percent volume diameter Dv $(50)(\mu \mathrm{m})$} \\
\hline & Measurement condition & Formulation ResQ-1 & Ventolin \\
\hline PARI LC & $5^{\circ} \mathrm{C}, \mathrm{RH} 50-70 \%$ & $3.696 \pm 0.075$ & $3.731 \pm 0.128$ \\
\hline \multirow[t]{2}{*}{$(2.2 \mu \mathrm{m})$} & $25 \pm 2^{\circ} \mathrm{C}, \mathrm{RH} 50-70 \%$ & $3.779 \pm 0.182$ & $3.845 \pm 0.036^{*}$ \\
\hline & $39 \pm 2^{\circ} \mathrm{C}, \mathrm{RH} 50-70 \%$ & $4.121 \pm 0.128 *$ & $4.17 \pm 0.08 * *$ \\
\hline PARI LC & $5^{\circ} \mathrm{C}, \mathrm{RH} 50-70 \%$ & $4.382 \pm 0.045$ & $4.08 \pm 0.17$ \\
\hline \multirow{2}{*}{$(2.9 \mu \mathrm{m})$} & $25 \pm 2^{\circ} \mathrm{C}$, RH $50-70 \%$ & $4.962 \pm 0.013^{*}$ & $4.492 \pm 0.06^{* *}$ \\
\hline & $39 \pm 2^{\circ} \mathrm{C}, \mathrm{RH} 50-70 \%$ & $5.474 \pm 0.230 *$ & $5.536 \pm 0.016^{* *}$ \\
\hline PARITIA & $5^{\circ} \mathrm{C}, \mathrm{RH} 50-70 \%$ & $5.278 \pm 0.059$ & $5.275 \pm 0.029$ \\
\hline \multirow[t]{2}{*}{$(8.6 \mu \mathrm{m})$} & $25 \pm 2^{\circ} \mathrm{C}, \mathrm{RH} 50-70 \%$ & $5.90 \pm 0.085^{* *}$ & $6.25 \pm 0.12 * *$ \\
\hline & $39 \pm 2^{\circ} \mathrm{C}, \mathrm{RH} 50-70 \%$ & $8.977 \pm 0.055^{* *}$ & $6.68 \pm 0.014 * *$ \\
\hline
\end{tabular}

$* P<0.05 ; * * P<0.01$ in comparison to $5^{\circ} \mathrm{C}$

frequency distribution of the particles recorded from the same test results.

The figure showed that there are two major populations of particles at $0.1-1$ and $1-100 \mu \mathrm{m}$ when the measurements were conducted at 5 and $25 \pm 2{ }^{\circ} \mathrm{C}$. The measurements of these two temperatures were consistent. However, the frequency distribution was different when measured at $39 \pm 2{ }^{\circ} \mathrm{C}$, and there was only one major population of particle size.

Figure $2 \mathrm{c}$ illustrated the cumulative change in volume percent compared with the increase in particle size of the aerosol droplets using PARI LC $(2.9 \mu \mathrm{m})$ and Ventolin. The results showed that there is an increase in volume distribution percent of particles when the relative humidity increased during measurement. The distribution volume measured at $\mathrm{RH}>90 \%$ was significantly different compared to that of RH $30-45 \%$ (Table III). There was a right shift of accumulation curves with decreasing relative humidity. Figure $2 \mathrm{~d}$ was a frequency distribution of the particles recorded from the same test results. The figure showed that there are two major populations of particles at $0.1-1$ and $1-100 \mu \mathrm{m}$ when measured at $\mathrm{RH}>$ $90 \%$. However, the frequency distribution was different when measured at $\mathrm{RH} 30-45 \%$, and there was only one major population of particle size.

\section{Comparison of Particle Deposition Measured by NGI when Used Individually and in Series with LD}

Particle deposition was first measured with NGI individually. The same measurement was conducted with NGI connected in series to the Spraytec LD instrument. To ensure the same aerosol and flow conditions, a metal adaptor was used to connect the NGI and Spraytec systems.

Two formulations of inhalation solution (ResQ-1 and Ventolin) were measured using the NGI at the same flow rate $(15 \mathrm{~L} / \mathrm{min})$ and with the same nebulizers. Histograms of drug deposition for different stages in NGI analysis are presented in Fig. 3.

The comparison of the results obtained from seven stages and MOC (Fig. 3) show excellent correspondence between measurements using NGI separate individually and in series (formulation ResQ-1, Fig. 3a, $t$ test, $P>0.05$; Ventolin inhalation solution, Fig. $3 b$, $t$ test, $P>0.05)$.

\section{Study of Consistency Between NGI and Spraytec Assessments of Nebulizer}

The comparison of NGI and Spraytec were completed using three types of nebulizers (PARI LC $(2.2 \mu \mathrm{m})$, PARI LC $(2.9 \mu \mathrm{m})$, and PARI TIA $(8.6 \mu \mathrm{m}))$ and two types of drug formulations (Ventolin and formulation ResQ-1). The data were measured simultaneously on the NGI and Spraytec instruments under the same ambient conditions $\left(5^{\circ} \mathrm{C}, \mathrm{RH} 50-70 \%\right)$. The histograms of the cumulative frequency corresponding to different particle size diameter were shown in Fig. 4. The cumulative frequencies of NGI were greater than that of the Spraytec when the particle size was less than $5.39 \mu \mathrm{m}$ (Fig. $4 \mathrm{a}-\mathrm{d}$ ). The results indicated an inconsistency between NGI and Spraytec measurements when using the PARI LC $(2.2 \mu \mathrm{m})$ and PARI LC $(2.9 \mu \mathrm{m})$ nebulizers. However, there is a good consistency between NGI and

Table III. Summary of the Value of Dv (50) Obtained with the Spraytec in Different Humidities by Using Three Types of Nebulizer

\begin{tabular}{llcc}
\hline & & The fifty percent volume diameter Dv $(50)(\mu \mathrm{m})$ \\
\cline { 2 - 4 } Device & Measurement condition & Formulation ResQ-1 & $3.748 \pm 0.046$ \\
\hline PARI LC & $25 \pm 2^{\circ} \mathrm{C}, \mathrm{RH}>90 \%$ & $3.620 \pm 0.037$ & $4.098 \pm 0.024 *$ \\
$(2.2 \mu \mathrm{m})$ & $25 \pm 2^{\circ} \mathrm{C}, \mathrm{RH} 30-45 \%$ & $3.982 \pm 0.064 *$ & $4.449 \pm 0.066$ \\
PARI LC & $25 \pm 2^{\circ} \mathrm{C}, \mathrm{RH}>90 \%$ & $4.680 \pm 0.147$ & $5.083 \pm 0.222^{*}$ \\
$(2.9 \mu \mathrm{m})$ & $25 \pm 2^{\circ} \mathrm{C}, \mathrm{RH} 30-45 \%$ & $5.011 \pm 0.057 *$ & $5.547 \pm 0.04$ \\
PARI TIA & $25 \pm 2^{\circ} \mathrm{C}, \mathrm{RH}>90 \%$ & $5.656 \pm 0.067$ & $6.318 \pm 0.101 *$ \\
$(8.6 \mu \mathrm{m})$ & $25 \pm 2^{\circ} \mathrm{C}, \mathrm{RH} 30-45 \%$ & $6.558 \pm 0.147 *$ & Ventolin \\
\hline
\end{tabular}

$* P<0.05 ; * * P<0.01$ in comparison to $\mathrm{RH}>90 \%$ 
a

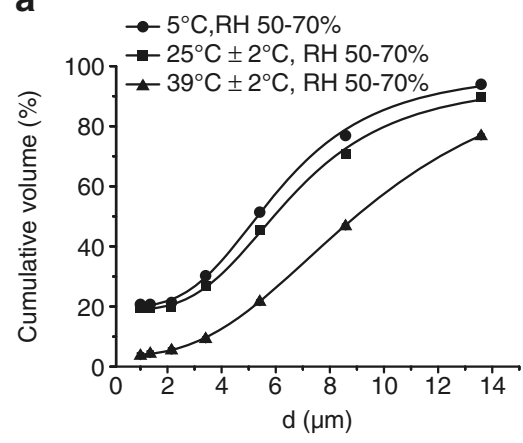

C

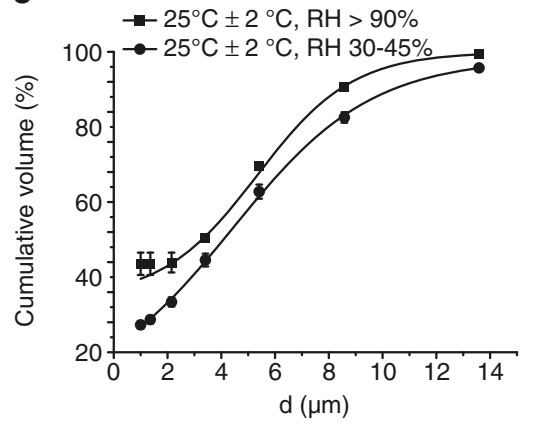

b

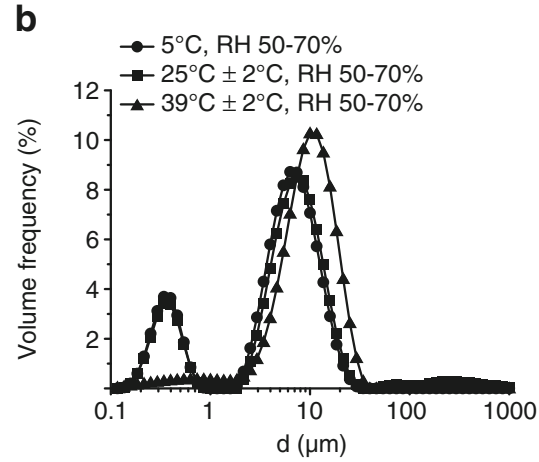

d

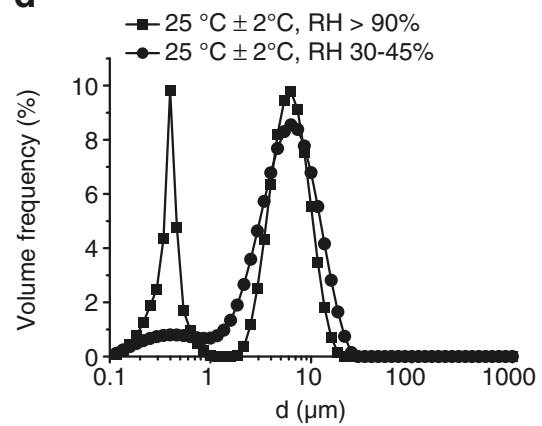

Fig. 2. A comparison of temperature and humidity on particle size characterization by laser diffraction. a, b Depict the effects of temperature on the assessment of formulation ResQ-1 and PARI TIA $(8.6 \mu \mathrm{m})$. $\mathbf{c}, \mathbf{d}$ Depict the effects of humidity on the assessment of Ventolin and PARI LC $(2.9 \mu \mathrm{m})$. a Shows the cumulative distribution of particle volume (formulation ResQ-1 and PARI TIA $(8.6 \mu \mathrm{m}))$, the curve shift right with temperature increase, and $\mathbf{b}$ is the frequency distribution of particle volumes (formulation ResQ-1 and PARI TIA $(8.6 \mu \mathrm{m}))$. There were two particle populations measured at 5 and $25 \pm 2^{\circ} \mathrm{C}$; however, the particle population under $1 \mu \mathrm{m}$ is below the detection limit when measured at $39 \pm 2^{\circ} \mathrm{C}$. c Shows the cumulative distribution of particle volumes (Ventolin and PARI LC $(2.9 \mu \mathrm{m})$ ), the curve shift right with relative humidity decrease, and $\mathbf{d}$ is the frequency distribution of particle volume (Ventolin and PARI LC $(2.9 \mu \mathrm{m})$ ). There were two particle populations when measured at $\mathrm{RH}>90 \%$ and $\mathrm{RH} 30-45 \%$

Spraytec measurements when using the PARI TIA than PARI LC nebulizers. When using the PARI TIA $(8.6 \mu \mathrm{m})$, the cumulative frequencies of Spraytec and NGI measurements were equivalent between the particle sizes 2.08 and $14.10 \mu \mathrm{m}$, but were slightly greater in Spraytec than in NGI when the particle size was less than $2.08 \mu \mathrm{m}$.
The linear correlation of the cumulative fraction (CF) yields for formulation ResQ-1 is shown in Fig. 5. The linear regression for PARI LC $(2.2 \mu \mathrm{m})$ is CF $($ Spraytec $)=1.19^{*} \mathrm{CF}(\mathrm{NGI})-30.6$ with $R^{2}=0.893$, and for PARI LC $(2.9 \mu \mathrm{m})$ is CF (Spraytec) $=0.90 * \mathrm{CF}$ (NGI)-0.60 with $R^{2}=0.878$. However, regression analysis of the data from PARI TIA $(8.6 \mu \mathrm{m})$ demonstrated a
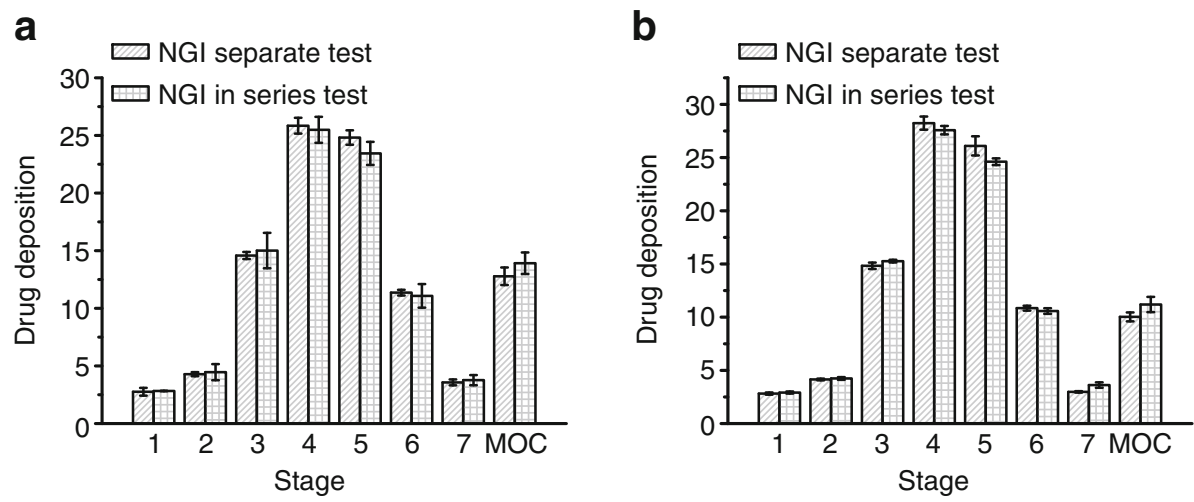

Fig. 3. The comparison of NGI separate and in series tests. a PARI LC $(2.2 \mu \mathrm{m})$ and formulation ResQ-1. b PARI LC $(2.2 \mu \mathrm{m})$ and Ventolin 
a
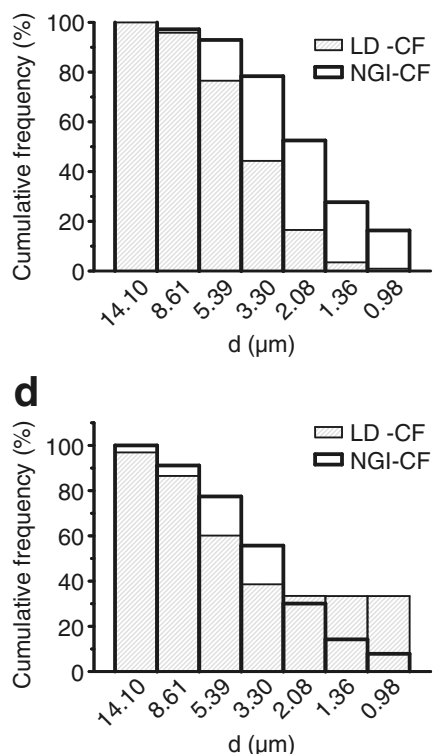

b

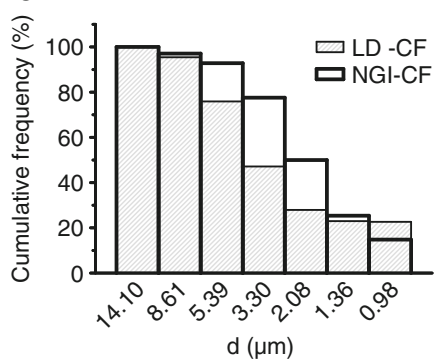

e

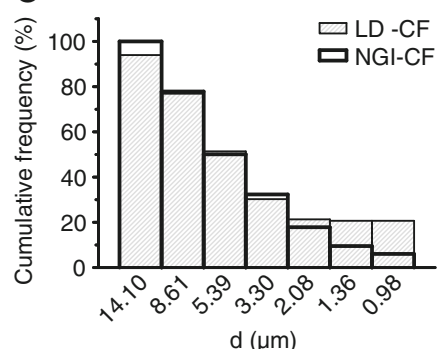

C

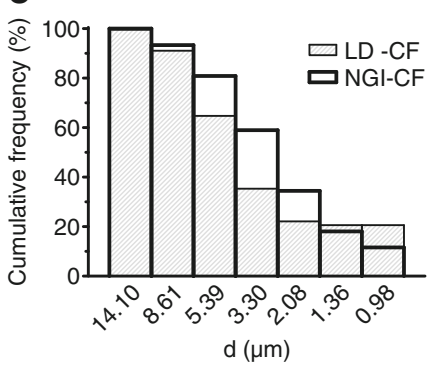

f

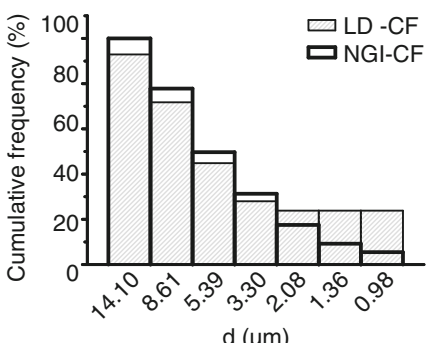

Fig. 4. Comparison of the cumulative frequency with simultaneous measurements for NGI and Spraytec. a Formulation ResQ-1 and PARI LC $(2.2 \mu \mathrm{m})$; b Ventolin and PARI LC $(2.2 \mu \mathrm{m})$; $\mathbf{c}$ formulation ResQ-1 and PARI LC $(2.9 \mu \mathrm{m})$; d Ventolin and PARI LC $(2.9 \mu \mathrm{m})$; e formulation ResQ-1 and PARI TIA $(8.6 \mu \mathrm{m})$; f Ventolin and PARI TIA $(8.6 \mu \mathrm{m})$

good correlation, $\mathrm{CF}($ Spraytec $)=0.83 * \mathrm{CF}(\mathrm{NGI})+$ 10.27 with $R^{2}=0.977$.

\section{DISCUSSION}

The Pharmacopeia does not require the environmental operating condition when evaluating the aerosol particle size by LD. In this study, we demonstrated that temperature and humidity are important factors with significant influence on the particle size distribution measurement using the Spraytec instrument in the evaluation of aerosol inhalations. The drug deposition of inhaled aerosol is significantly different when the measurements were conducted at different ambient temperature or humidity.

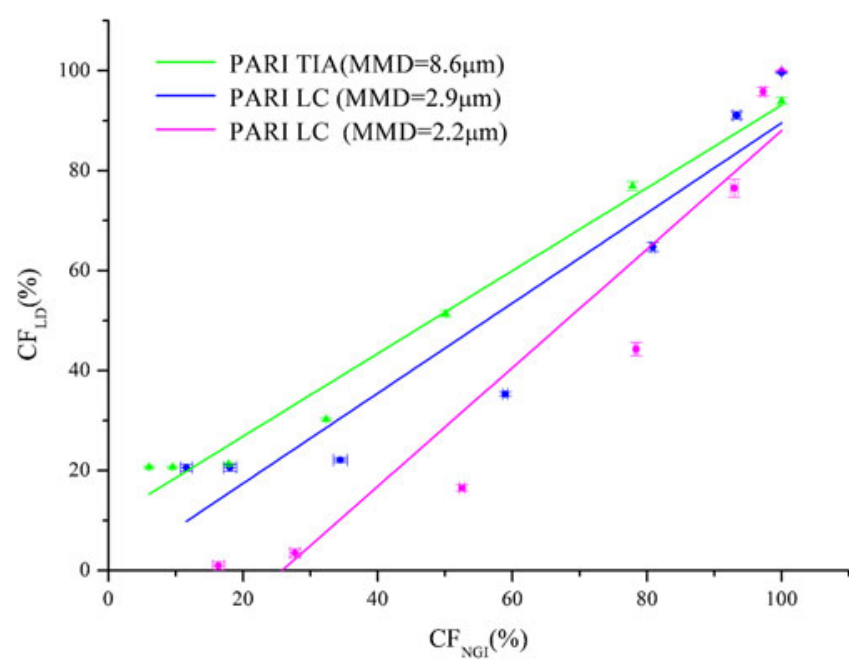

Fig. 5. The correlation curves of NGI and Spraytec for nebulizers with different particle sizes
Particles with a diameter less than $1 \mu \mathrm{m}$ were undetectable at $39^{\circ} \mathrm{C}$ compared to $5^{\circ} \mathrm{C}$. The same result was observed when at $\mathrm{RH} 30-45 \%$ was compared to $\mathrm{RH}>90 \%$ (Fig. 2). This outcome is likely due to the fact that small particles with higher specific surface area are easily evaporated. The Spraytec instrument was equipped with a metal inhalation cell to minimize the perturbations resulting from the environment. However, the metal cell can also be a good conductor of heat to or from the ambient environment. The temperature in inhalation cell may rapidly increase as the increase of temperature in the regulated chamber. It may result in the significant effect of temperature on the performance of the Spraytec instrument.

Small particles $(<1 \mu \mathrm{m})$ are likely to be deposited deep in the lung and therefore they are particularly important in the evaluation of aerosol inhalation (10). Commonly used parameters such as MMAD and cumulative PSD can be significantly changed by the population of small particles. Therefore, it is necessary to consider the influence of temperature and humidity on aerosol measurement when the Spraytec instrument is used. The optimum operating condition in $\mathrm{LD}$ is in $5^{\circ} \mathrm{C}$ or in $\mathrm{RH}>90 \%$. Our result is in accordance with a previous report by Ziegler et al. in which a special soft mist inhaler and different LD equipment were used (17).

The recent trend of systemic pulmonary drug delivery makes it very important to understand the correlation between the aerodynamic diameter, determined by in vitro measurements or in vivo lung deposition studies, and different geometric diameters measured by a variety of nonaerodynamic techniques (13). LD provides a volume distribution of the geometric diameter (diameter of a sphere with the same volume) while the inertial impaction provides the aerodynamic diameter (diameter of a sphere with a unit density having the same velocity as the droplet) (40). In pharmaceutical practice, the operating condition can be well 
controlled. The Pharmacopeia have fixed $5^{\circ} \mathrm{C}$ as the NGI optimum operating condition (22). In this study, the same optimum operating condition has been found in the LD instrument. Therefore, to explore the correlation between two NGI and LD, both two different instruments have been operated in the optimum operating condition (in $5^{\circ} \mathrm{C}$ ).

We found a poor correlation between NGI and Spraytec analyzers by comparing the results of the two measurements. This result is more pronounced when the particles are generated by different nebulizers, such as the PARI LC $(2.2 \mu \mathrm{m})$ and PARI LC $(2.9 \mu \mathrm{m})$. However, a relatively good correlation $\left(R^{2}=0.977\right)$ between NGI and Spraytec analyzers was observed with larger size particles generated by the PARI TIA $(8.6 \mu \mathrm{m})$ nebulizer (Fig. 5).

It is notable that findings above comparing NGI to laser diffraction measurements are contrary to previous reports that compared ACI to laser diffraction.

The previous report indicated good correlation and consistency in measurements between inertial impaction (ACI) and laser diffraction methods (17).

The poor consistency or poor correlation cannot be attributed to the in series set-up of NGI and Spraytec instruments, because the NGI measurements are well correlated and consistent when used individually or in series with the Spraytec instrument for evaluation of the same aerosol (Fig. 3).

\section{CONCLUSION}

This study investigated the effects of temperature and humidity on the particle sizing of nebulizer by LD and compared the consistency in particle size measurement between NGI and LD. The study found that the assessment of nebulizer by LD was significantly affected by either temperature or humidity, and an optimum result could be yielded at $5^{\circ} \mathrm{C}$ or RH $>90 \%$. Furthermore, this study found that there was an inconsistency in the assessment of nebulizer between LD and NGI when both of the apparatuses were operated at optimum conditions. In addition, the particle size generated by different jet nebulizers could also have a great impact on the assessment by either LD or NGI. These differences should be taken into consideration in the evaluation of the qualities of nebulizer products in pharmaceutical practice.

\section{ACKNOWLEDGMENTS}

We gratefully acknowledge all the participants that made this work possible. We thank Key-Pharma Biomedical Inc. for providing formulation ResQ-1. We also thank Xuebing Li, Peng Lu (Member of Malvern Instrument Research Center) for their help with the particle size calibration of Spraytec.

\section{REFERENCES}

1. Nagao LM, Lyapustina S, Munos MK, Capizzi MD. Aspects of particle science and regulation in pharmaceutical inhalation drug products. Cryst Growth Des. 2005;5:2261-7.
2. Le Brun PPH, De Boer AH, Heijerman HGM, Frijlink HW. A review of the technical aspects of drug nebulization. Pharm Word Sci. 2000;22:75-81.

3. Jaafar-Maalej C, Andrieu V, Elaissari A, Fessi H. Assessment methods of inhaled aerosols: technical aspects and applications. Drug Deliv. 2009;6:941-59.

4. Glenn LK, Frank PP. Metered-dose inhalers and nebulizers in the acute setting. AnnPharmacother. 1992;26:92-5.

5. Gibbons A, Smyth HDC. Science and technology of nebulizers and liquid-based aerosol generators. In: Hugh D.C. Smyth, Anthony J.Hickey, editors. Controlled pulmonary drug delivery. 2011. doi: 10.1007/978-1-4419-9745-6. p.232-245.

6. Chatburn RL, McPeck M. A new system for understanding nebulizer performance. Respir Care. 2007;52:1037-50.

7. Dhand R. Nebulizers that use a vibrating mesh or plate with multiple apertures to generate aerosol. Respir Care. 2002;47(12):1406-16.

8. Mercer TT. Production of therapeutic aerosols: principles and techniques. Chest. 433 1981;80(6 Suppl):813-8.

9. Sterk PJ, Plomp A, van de Vate JF, Quanjer PH. Physical properties of aerosols produced by several jet- and ultrasonic nebulizers. Bull Eur Physiopathol Respir. 1984;20(1):65-72.

10. Khilnani GC, Banga A. Aerosol therapy. Indian J Chest Diseases Allied Sci. 2008;50:209-20.

11. O'Callaghan C, Barry PW. The science of nebulized drug delivery. Thorax. 1997;440(52):s31-44.

12. Bosquillon C, Rouxhet PG, Ahimou F, Simon D, Culot C, Pre'at $\mathrm{V}$, et al. Aerosolization properties, surface composition and physical state of spray-dried protein powders. J Control Release. 2004;99(3):357-67.

13. Boris YS, Pratibhash C, Henry HYT, Albert HLC. Particle size analysis in pharmaceutics: principles, methods and applications. Pharm Res. 2006;2:203-27.

14. Mitchell JP, Nagel MW. Particle size analysis of aerosols from medicinal inhalers. KONA. 2004;22:32-64.

15. de Boer AH, Gjaltema D, Hagedoorn P, Frijlink HW. Characterization of inhalation aerosols: a critical evaluation of cascade impactor analysis and laser diffraction technique. Int $\mathbf{J}$ Pharm. 2002;249(1-2):219-31.

16. Kwong WT, Ho SL, Coates AL. Comparison of nebulized particle size distribution with Malvern laser diffraction analyzer versus Andersen cascade impactor and low-flow Marple personal cascade impactor. J Aerosol Med. 2000;13(4):303-14.

17. Ziegler J, Wachtel H. Comparison of cascade impaction and laser diffraction for particle size distribution measurements. J Aerosol Med. 2005;18(3):311-24.

18. Zhang XM, Liu Q, Hu JH, Xu L, Tan W. An aerosol formulation of R-salbutamol sulfate for pulmonary inhalation. Acta Pharmaceutica Sinica B. 2014;4(1):79-85.

19. Shan ZY, Tan YH, Qin LZ, Li G, Pan X, Wang ZH, et al. Formulation and evaluation of novel reverse microemulsions containing salmon calcitonin in hydrofluoroalkane propellants. Int J Pharm. 2014;466:390-9.

20. Cheng YS. Mechanisms of pharmaceutical aerosol deposition in the respiratory tract. AAPS PharmSciTech. 2014;15(3):630-40.

21. Marple VA, Olson BA, Miller NC. The role of inertial particle collectors in evaluating pharmaceutical aerosol delivery systems. J Aerosol Med. 1998;11((suppl 465 1)):139-53.

22. Preparations for nebulisation: characterization, general chapter 2.9.44. Pharmacopoeia 2012: p3803-3805.

23. Ma Z, Merkus HG, de Smet JGAE, Heffels C, Scarlett B. New developments in particle characterization by laser diffraction: size and shape. Powder Technol. 2000;111(1):66-78.

24. Orla NMM, Kevin MGT, Marian T, Anthony JT. Nebulization of fluids of different physicochemical properties with air-jet and ultrasonic nebulizers. Pharm Res. 1995;12(11):1682-8.

25. Meer SH, Raymond WML. Effect of particle shape on dry particle inhalation:study of flowability, aerosolization, and deposition properties. AAPS PharmSciTech. 2009;10(4):1252-62.

26. Martin GP, MacRitchie HB, Marriott C, Zeng XM. Characterization of a carrier-free dry powder aerosol formulation using inertial impaction and laser diffraction. Pharm Res. 2006;23(9):2210-9. 
27. Zeng XM, MacRitchie HB, Marriott C, Martin GP. Correlation between inertial impaction and laser diffraction sizing data for aerosolized carrier-based dry powder formulations. Pharm Res. 2006;23(9):2200-9.

28. Pilcer G, Vanderbist F, Amighi K. Correlations between cascade impactor analysis and laser diffraction techniques for the determination of the particle size of aerosolised powder formulations. Int J Pharm. 2008;358(1-2):75-81.

29. Alfred H, Madhu SS, Henrik K, Mandip S. Evaluation of the Malvern Spraytec with inhalation cell for the measurement of particle size distribution from metered dose inhalers. J Pharm Sci. 2004;93(2):349-63.

30. Jolyon M, Richard B, Svetlana L, Terrence T, Volker G. Nonimpactor-based methods for sizing of aerosols emitted from orally inhaled and nasal drug products (OINDPs). AAPS PharmSciTech. 2011;12(3):965-88.

31. Vecellio NL, Grimbert D, Becquemin MH, Boissinot E, Le PA, Lemarie' E, et al. Validation of laser diffraction method as a substitute for cascade impaction in the European project for a nebulizer standard. J Aerosol Med. 2001;14(1):107-14.

32. Murtomaa M, Mellin V, Harjunen P, Lankinen T, Laine E, Lehto VP. Effect of particle morphology on the tribo-electrification in dry powder inhalers. Int J Pharm. 2004;497(282):107-14.

33. Paul MY, Adrian S, Daniela T, Philip K, Herbert C, Hak-Kim C. Influence of humidity on the electrostatic charge and aerosol performance of dry powder inhaler carrier based systems. Pharm Res. 2007;24(5):963-70.

34. Young PM, Price R, Tobyn MJ, Buttrum M, Dey F. Effect of humidity on aerosolization of micronized drugs. Drug dev ind pharm. 2003;29(9):959-66.

35. Dennis JH. Nebulizer efficiency: modeling versus in vitro testing. Resp Care. 2007;52(8):984-8.

36. Farzin MS, Susan H, David L, Tanya C, Reinhard V, Warren HF. In vitro investigation of the effect of ambient humidity on regional delivered dose with solution and suspension MDIs. J Aerosol Med Pulm Drug Deliv. 2013;26(4):215-22.

37. Dennis J, Berg E, Sandell D, Ali A, Lamb P, Tservistas M, et al. Cooling the NGI-an approach to size a nebulised aerosol more accurately. Pharm Sci Notes. 2008;2008(1):1-4.

38. Berlinski A, Hayden JB. Optimization of a procedure used to measure aerosol characteristics of nebulized solutions using a cooled next generation impactor. J Aerosol Med Pulm Drug Deliv. 2010;23:397-404.

39. National Pharmacopoeia Committee. Pharmacopoeia of The People' s Republic of China. Part 2. Beijing: China Medical Science Press. 2010; Texts:p980.

40. Lelong N, Junqua-Moullet A, Diot P, Vecellio L. Comparison of laser diffraction measurements by Mastersizer $\mathrm{X}$ and Spraytec to characterize droplet size distribution of medical liquid aerosols. J Aerosol Med. 2014;27(2):94-102. 